\title{
La vida como parcialidad: un itinerario para la resistencia
}

\author{
Life as partiality: an itinerary for resistance
}

\section{Tuillang Yuing Alfaro*}

Universidad de Playa Ancha, Valparaíso, Región de Valparaíso, Chile

\section{Resumen}

El artículo pretende constituirse como un itinerario para aproximarse, por una parte, a la noción de vida que es sugerida por Deleuze a lo largo de su obra. En segundo lugar, pretende echar luz sobre el carácter específico de esta noción de vida en cuanto implica un momento de resistencia. Con este propósito, se revisa el sentido político de la vida en cuanto momento de evasión e invención al interior del juego de relaciones de poder. Para ello, una revisión de la lectura que hace Deleuze de la analítica del poder de Foucault es indispensable. Desde estas mismas consideraciones, se vislumbra un momento posterior en que es necesario dar cuenta de los aportes del saber más formal sobre la vida. Se trata en este punto de captar la noción de vida como aquello que resiste a la muerte, desbordando el plano meramente biológico para superponerse con el plano de la resistencia al poder. Para ello se hilvana un debate que va desde la conformación de la biología moderna hasta los aportes de Canguilhem. Las figuras de Bichat y

TYA: Doctor en Filosofía, e-mail: tuillangyuing@gmail.com 
Foucault son nuevamente relevantes para lo anterior. Finalmente, en el momento de las conclusiones se muestra cómo Deleuze, a través de una conjunción íntima entre pensamiento y vida, es capaz de poner en resonancia ambas esferas. Desde esta operación se muestran algunas proyecciones y retos teóricos eventuales que, lejos de resolver las interrogantes, hacen más denso y complejo el desafío de aproximarse a la vida.

Palabras clave: Deleuze .Vida. Resistencia. Pensamiento.

\section{Abstract}

This paper intends to establish itself, in the first place, as an itinerary to connect to life's notions, suggested by Deleuze across his work. It, then, seeks to enlighten the specific sense of this notion when it implies a resistance moment. With this purpose we examine the political meaning of life, as a moment of evasion and invention in the game of power relations. In order to achieve that, Deleuze's lecture of Foucault's analytics of power is crucial. From these considerations we see a subsequent moment in which it is necessary to account for the contributions of formal knowledge to life. It tries to capture the idea of life as a entity that resists death, leaving the biological side to override the side of resistance to power. In order to achieve this, we reconsider the debate that goes from the conformation of modern biology to Canguilhem's contributions. Bichat and Foucault become relevant again. Finally, in conclusion we show how Deleuze, through an intimate union between thought and life, is able to do dialogue both fields. From this operation, we can show some projections and eventual theorical challenges that, instead of solving the problem, make the challenge to approached life even denser and more complex.

Keywords: Deleuze. Life. Resistance. Thought.

Tout ce que j'ai écrit était vitaliste.

Deleuze (1990) 


\section{Introducción}

Un fragmento de una novela de Mishima (2003) permite sugerir la pregunta que guía la siguiente exploración:

El cuello desollado, que yacía airosamente en el suelo, parecía llevar una máscara de gato. El gato era solamente lo exterior; la vida se había hecho pasar por un gato (p. 60-61).

Que una particular forma de vida no sea más que el disfraz de una instancia que se resta a toda definición, parece ser una sentencia de toda pregunta que hace de la vida la dirección de su denuedo. La vida se escapa, regatea, se oculta aun cuando se persiga develar sus misterios con un cuchillo. Gilles Deleuze no está ajeno a esta obstinación. Para él, nos parece, la noción de vida representa también un momento de pura indeterminación: virtualidad potente inaprehensible que rehúye todo gesto de fijación. A la vez, para Deleuze, la vida indica la posibilidad de una resistencia que es política, y que además, compromete una manera de ejercer el pensar. Nuestro propósito será entonces descifrar las implicancias contenidas en la noción de vida que sugiere Deleuze para preguntar por el sentido que esta guarda cuando es considerada como foco de resistencia. Para ello, deberemos dar cuenta de algunos interlocutores que colaboran en este debate. Con especial atención deberemos detenernos en la lectura que hace Deleuze de la obra de Michel Foucault, puesto que contiene, en otras severas cuestiones, un desarrollo en torno a la vida como elemento capaz de resistir al poder. Se trata, en este sentido, de la posibilidad de recorrer una reflexión en torno a la vida que es decisiva para la filosofía contemporánea. Desde luego, esto significa apelar a otros aportes y reflexiones para de este modo elaborar el itinerario de un problema cuya densidad invita siempre a una relectura. Finalmente, más que establecer antecedentes teóricos o causales intelectuales en la noción de vida que se deja ver en la obra de Deleuze, se trata también de tomar noticia del decurso en relación a otras posturas que lo han hecho suyo. Podremos ver así que otras 
voces - entre las que destacan Foucault, Bichat, Agamben, Stengers y otros - participan de consonancia que apunta a mostrar lo que está a la base de la vida como organización parcial.

\section{El momento de la inmanencia}

En un texto que guarda un cierto carácter testamentario, Gilles Deleuze describe la vida como un puro plano de inmanencia lejos de cualquier contrato de sentido con un sujeto que le codifique: "Se dirá que la pura inmanencia es UNA VIDA, y nada más." (2007, p. 37). No es casual que Deleuze utilice el "se" (en francés On dira): esta partícula redobla el compromiso impersonal de este plano anterior que no refiere a ningún "yo", a ningún ser delimitado: "No es la inmanencia de la vida, sino que lo inmanente es en sí mismo una vida" (DELEUZE, 2007, p. 37). De este modo, se pone en forma un "sí mismo" que no descansa en ninguna alteridad, en ningún juego de oposiciones identitarias, en ninguna alusión a una conciencia o a un objeto al que esta pudiese estar dirigida.

A nuestro parecer, dos aspectos deben desarrollarse para clarificar el sentido de esta inmanencia e intentar un balance de sus alcances. Por una parte, debe indagarse la implicancia de la noción de vida en su consistencia política: para Deleuze, la vida es simultáneamente el punto de aplicación y de resistencia al poder. En este último punto la referencia a Foucault se hace ineludible. Por otro lado, debe establecerse también el lugar de los aportes provenientes de las ciencias de la vida en los que la noción de vida ha tenido una trayectoria no exenta de espesura filosófica. Intentaremos ir dando cuenta de los debates implicados en ambas trayectorias.

\section{La vida frente al poder}

Recordemos que desde mediados de los setenta, Foucault va elaborando de modo paulatino la noción de biopolítica como aquella 
perspectiva que permite acercarse a aquel panorama en que las relaciones de poder atraviesan ya no la individualidad del cuerpo - como en el caso de las disciplinas - , sino los procesos vitales de la sociedad en su conjunto (FOUCAULT, 1998; 2001). En el marco de un giro al interior de su analítica del poder, la biopolítica permite a Foucault hacerse cargo de los problemas vitales del conjunto, vale decir, los fenómenos de población. El punto a destacar en estos análisis es la arremetida sobre la vida por parte del poder. Según Foucault, desde esta perspectiva se implementa un poder que se ejerce sobre la vida. Se trata, en efecto, de una racionalidad que toma a la población para "hacerla vivir" de un modo determinado, esperando de ella el amoldamiento a regulaciones normativas laxas pero manifiestas cuyo resultado es la medida y administración del hombre-especie, del viviente colectivo.

Con todo, desde otra mirada, esta administración de la vida en base a la norma indica un cuidado del proceso productivo y reproductivo de la vida misma. Lejos de una negación o de un cuidado exhaustivo, el poder se contenta con vigilar y supervisar procesos ya existentes que permiten la perpetuación de una vida que, en ese sentido, se produce a sí misma (FOUCAULT, 1998; 2001).

Ahora bien, con ocasión de su texto dedicado a Foucault, Deleuze (1987) se detiene en los recovecos de este giro conceptual. Por una parte, advierte que la cuestión de la vida estaba presente en Foucault desde el período que se denomina arqueológico, principalmente en Nacimiento de la clínica y Las palabras y las cosas. Sin embargo, valiéndose de la posibilidad de una lectura retrospectiva de la obra de Foucault, Deleuze muestra cómo la noción de vida tiene una vinculación necesaria e íntima con la noción de fuerza, la que está al centro de la propuesta metodológica de Foucault para incorporar el poder en sus análisis. En efecto, para Deleuze, la densidad del anuncio de la "muerte del hombre" hecho por Foucault en 1966 lleva implícita una puesta en forma de aquellas fuerzas que constituyen al hombre y que lo ponen en relación con otras escenas.

Según Deleuze, las fuerzas que actualizan y dan forma al hombre tal y como es notificado por Foucault, son las de la vida, las del trabajo y del lenguaje. Así, se dan cita esferas diversas que comparten el finiquito de toda instancia representativa que sea garantía de 
un orden natural. Vemos entonces cómo Deleuze advierte agudamente que la cuestión de la vida estaba ya en el momento "arqueológico" de Foucault, y cómo ella se hallaba emparentada estrechamente con la cuestión de las fuerzas que va a signar el debate sobre el poder. Con todo, si profundizamos en el desarrollo que hace Foucault, podemos ver que su análisis apunta a la emergencia de fundamentos que desbordan toda temporalidad fija u organizable bajo parámetros humanos. La débil figura del hombre tiene lugar a la luz de positividades que le son constitutivas pero de las que siempre obtiene una posición sucedánea. El hombre, entonces, se encuentra inserto en una historia que ya no le pertenece, de la que no es bajo ningún respecto protagonista:

[...] cuando trata de definirse como ser vivo, sólo descubre su propio comienzo sobre el fondo de una vida que se inició mucho antes que él; cuando trata de retomarse como ser que trabaja, sólo saca a la luz las formas más rudimentarias en el interior de un tiempo y de un espacio humanos ya institucionalizados, ya dominados por la sociedad; y cuando trata de definir su esencia de sujeto parlante, más acá de cualquier lengua efectivamente constituida, no encuentra sino la posibilidad ya desplegada del lenguaje y no el balbuceo [...] (FOUCAULT, 2002, p. 321).

Teniendo en vista estos alcances, Deleuze profundiza sobre estos puntos:

Eso es lo esencial en MC [Las palabras y las cosas]: Foucault no dice que la vida, el trabajo y el lenguaje sean fuerzas del hombre de las que éste toma conciencia como de su propia finitud. Al contrario, la vida, el trabajo, el lenguaje surgen en primer lugar como fuerzas finitas exteriores al hombre, que le imponen una historia que no es la suya. Sólo en un segundo momento el hombre se apropia de esa historia, convierte su propia finitud en un fundamento (DELEUZE, 1987, p. 118).

¿Pero a qué se refieren cuando hablan de vida tanto Foucault como Deleuze? ¿Y cómo ella puede establecer un pacto de sentido con las fuerzas y con las relaciones de poder?

Pues bien, como ya hemos señalado, las relaciones de fuerza son las que están a la base de la analítica del poder que Foucault propone. 
Y Deleuze ha sido un lector atento de esta perspectiva. En efecto, es Deleuze quien ha sistematizado y organizado los elementos que marcan, en Foucault, una distancia respecto de otros modos de concebir y analizar el poder (MOREY, 1981). Deleuze enfatiza el que Foucault describa el poder como una relación de fuerzas (rapport de force), y así, al hablar del poder, lo relacional se impone a lo sustantivo, evacuando todo coeficiente de autonomía. La fuerza puede concebirse como una acción que se ejerce sobre otra acción posible o eventual con el fin de generar, producir o construir algo en la realidad. En este sentido relación de poder y fuerza son equivalentes. En palabras de Deleuze: “Una fuerza siempre es afectada desde afuera por otras" (DELEUZE, 1987, p. 118). En definitiva, este rasgo de suma de fuerzas, es el que comunica el carácter productivo y creativo del poder.

Con todo, para nuestro propósito es interesante que Deleuze preste atención a la afirmación de Foucault en La voluntad de saber, según la cual:

donde hay poder hay resistencia, y no obstante (o mejor: por lo mismo), esta nunca está en posición de exterioridad respecto del poder. ¿Hay que decir que está necesariamente en el poder, que no es posible escapar de él, que no hay, en relación con él exterior absoluto, puesto que se estaría infaltablemente sometido a la ley? [...] Eso sería desconocer el carácter estrictamente relacional de las relaciones de poder. No pueden existir más que en función de una multiplicidad de puntos de resistencia: estos desempeñan, en las relaciones de poder, el papel de adversario, de blanco, de apoyo, de saliente para una aprehensión. Los puntos de resistencia están presentes en todas partes dentro de la red de poder (FOUCAULT, 1998, p. 116).

La voluntad de saber, daba cuenta de esta co-implicancia: donde hay poder debe haber algo que se le opone, y en esa misma medida asecha siempre la posibilidad de una inversión en las relaciones de poder. Foucault es optimista en 1976 para dar cuenta de este nudo: la resistencia no es sólo una contrapartida, "no por eso son engaño o promesa necesariamente frustrada" (FOUCAULT, 1998, p. 117). Al contrario, los focos de resistencia actuarán: 
[...] encendiendo algunos puntos del cuerpo, ciertos momentos de la vida, determinados tipos de comportamiento [...] rompiendo unidades y suscitando reagrupamientos, abriendo surcos en el interior de los propios individuos, cortándolos en trozos y remodelándolos, trazando en ellos, en su cuerpo y su alma, regiones irreducibles (FOUCAULT, 1998, p. 117).

Precisamente, para Deleuze, es relevante atender a esta dislocación según la cual, en un escenario donde las relaciones de poder toman a su cargo una cierta gestión de la vida, va a ser esta -la vida-, la que va a señalar el punto más severo de resistencia. Al mismo tiempo, la resistencia va a ser un punto de evasión que nunca llega a ser totalmente capturado puesto que es, en cierta medida, anterior al poder. Dicho de otro modo, aquel coeficiente de resistencia presente en toda relación de poder consiste no en una toma de distancia ajena a todo influjo de las fuerzas. Muy por el contrario, la resistencia tiene lugar como un punto que, al interior mismo del conflicto de las fuerzas, se constituye como aquel punto de fuga de pura potencialidad que sorprende toda anticipación y se resta de la dicotomía de las fuerzas en tensión. Dice Deleuze:

En ese sentido, la fuerza dispone de un potencial con relación al diagrama en el que está incluida, o de un tercer poder que se presenta como capacidad de «resistencia» [...] Es más, la última palabra del poder es que la resistencia es primera, en la medida en que las relaciones de poder se mantienen intactas en el diagrama, mientras que las resistencias están necesariamente en una relación directa con el afuera del que proceden los diagramas (DELEUZE, 1987, p. 119).

No debe sorprender entonces que esa potencia imprevisible, ese momento de indeterminación que se resta permanentemente a una codificación definitiva, sea para Deleuze, identificado con la vida. No obstante, la vida manifiesta su carácter de fuerza en forma proporcional a 
la retirada de la figura del hombre como una figura codificada universalmente - en este caso bajo la forma del "sujeto de derechos ${ }^{1 \text { ". }}$

Así, el hombre y el sujeto de derechos no son sino cualificaciones que capturan de modo efímero las fuerzas de la vida sin llegar nunca a inmovilizarlas. Y a su vez, la vida se constituye entonces como esa instancia que se resiste permanentemente a todo modo de representación definitivo.

Es por lo anterior que Deleuze se detiene con sutileza en la aparición de un nuevo modo de aplicación del poder, a saber, el del biopoder. En este diagrama "la vida surge como nuevo objeto de poder" (DELEUZE, 1987, p. 121) y las antiguas formas del derecho y la legalidad, hacen de la vida su fundamento definitivo. La vida, en cuanto objeto del poder se vuelve entonces el sostén y la causa de acciones de dominio y escisiones al interior del espectro de "lo vivo". Sin embargo, al ser la vida el punto de aplicación más encarnizado del poder, ella misma gana un estatuto de resistencia de mayor privilegio y con posibilidades permanentes de fuga (STENGERS, 2000):

Ahora bien, cuando el poder toma así la vida por objeto u objetivo, la resistencia al poder ya invoca la vida y la vuelve contra el poder [...] Cuando el poder deviene biopoder, la resistencia deviene poder de la vida, poder vital que no se deja detener en las especies, en los medios y en los caminos de tal y tal diagrama (DELEUZE, 1987, p. 122).

En definitiva, es esta tensión entre control y espontaneidad la que es leída por Deleuze como la integración de la vida en el juego de los dispositivos (DELEUZE, 1990, p. 240-247). La vida, a partir de ese original contrato con el poder, deviene un distrito codificado, objeto de enunciaciones, agenciamientos y apropiaciones. La vida se hace objeto

1 Se advierte, en este punto, de una de las críticas más severas de Deleuze al humanismo de pretensiones trascendentales que está presente en varias de sus obras. (DELEUZE, 1987, 2005 y 2008). Una discusión sintética sobre el tenor biopolítico del derecho moderno puede seguirse en NAPOLI, 2000. En este trabajo el autor revisa las limitaciones que encuentra la racionalidad jurídica a la hora de establecer una noción positiva de la vida, obligando a una definición puramente funcional: "El derecho no ha sido capaz de oponer a la estrategia del biopoder una concepción alternativa de la vida (NAPOLI, 2000, p. 58. La traducción es nuestra). Una perspectiva que asume los distintos aspectos del debate como un desafío genealógico se encuentra en BROSSAT, 2010. 
de cartografías que detallan y organizan sus modos de emergencia, pero al mismo tiempo integra un coeficiente permanente de evasión, una fuerza que persiste en la novedad y la imprevisibilidad.

Ahora bien, esta característica de la vida es interpretada como resistencia. No obstante, esta afirmación nos lleva a una ambigüedad semántica que tiene decisivas implicancias filosóficas. ¿A qué resiste la vida? La respuesta a esta pregunta puede ser doble: la vida resiste al poder - como Foucault y Deleuze lo sugieren -, pero la vida resiste también a la muerte, a su propia degradación, como también Foucault y Deleuze han advertido también, en este caso, de la mano de Xavier Bichat (1852). En efecto, lo sustantivo en Bichat es su distinción entre una muerte violenta - la interrupción de las funciones vegetativas -, y la muerte natural que adviene como una degradación progresiva. De este modo, la vida es cómplice íntima de una muerte que se despliega diversa, hormigueante y paulatina a lo largo de la vida. La inversión de estas consideraciones permite a Bichat enunciar una definición litigante de la vida como aquello que resiste a la muerte. Sobre esto señala Deleuze:

\begin{abstract}
¿No es la vida esa capacidad de resistir de la fuerza? Desde El nacimiento de la clínica, Foucault admiraba a Bichat por haber inventado un nuevo vitalismo al definir la vida por el conjunto funciones que resisten a la muerte. $\mathrm{Y}$ es en el hombre donde hay que buscar, tanto en el caso de Foucault como el de Nietzsche, el conjunto de las fuerzas y funciones que resisten... a la muerte del hombre. Spinoza decía: no se sabe lo que puede un cuerpo humano cuando se libera de las disciplinas del hombre. Y Foucault: no se sabe lo que puede el hombre «en tanto que está vivo», como conjunto de «fuerzas que resisten» (DELEUZE, 1987, p. 123).
\end{abstract}

Esta lectura de Deleuze plantea un desafío. Da la impresión de que el análisis comunica dos planos cuyo nexo no es del todo nítido. ¿No es acaso la interpretación de Foucault sobre Bichat una cuestión que se sitúa en el campo de la constitución del saber clínico? ¿No es esta resistencia una mera manifestación de procesos orgánicos evacuados de todo sentido de politicidad? ¿Cómo podría vincularse esta 
resistencia a los procesos degenerativos con una resistencia afirmativa al poder?

El reto consiste entonces en seguir la trama que permite pasar de una resistencia comprendida en el ámbito estricto de la fisiología a otro en que esa resistencia hace referencia al poder y que, por tanto, bien puede ser calificada como política. Para comprender esto será nuestra tarea analizar con mayor detalle el aporte del ámbito de las ciencias de la vida.

\section{La vida frente al conocimiento de la vida}

En numerosos comentarios, se puede constatar que Deleuze no está al margen de las discusiones en torno al fundamento conceptual que tiene la biología entre los siglos XVIII y XIX (DELEUZE, 2008). Se trata, en términos muy generales, del momento en que aparece la noción de organismo como núcleo teórico y metodológico que conduce el conocimiento de lo viviente en formas diversas y heterogéneas. Así, por ejemplo, tomando recaudo de las mutaciones históricas del saber moderno que pone en forma la figura del hombre, Deleuze indica:

Con Jussieu, Vicq d'Azyr y Lamarck, la coordinación y la subordinación de los caracteres, en una planta o en un animal, en resumen, una fuerza de organización impone una distribución de organismos que ya no se dejan alinear, sino que tienden a desarrollarse cada uno por su cuenta (la anatomía patológica acentúa esta tendencia al descubrir una profundidad orgánica o un "volumen patológico" (DELEUZE, 1987, p. 163).

Estos pasajes acusan, a nuestro juicio, una serie de debates y aproximaciones que dialogan con la noción de vida que construye Deleuze y que ameritan una cierta demora. Con todo, si se tiene en cuenta el diálogo con Foucault que en ellos está a la base, hay que asumir, en parte el recorrido que éste último propone. En efecto, en Las palabras y las cosas, Foucault indica que a fines del siglo XVIII, la empresa de agrupación y clasificación de un orden general de los seres vivos según sus caracteres desviará su mirada hacia un espacio de invisibilidad que 
tiene lugar en la interioridad de los seres: la organización (FOUCAULT, 2002). De este modo, los caracteres visibles se solapan tras un dominio fundamental que estructura la funcionalidad del viviente respecto de un modo determinado de vivir. En este sentido, la emergencia del principio de organización se expresa, desde mediados del siglo XVIII, como formas de relación que inauguran el campo de la biología. Primeramente, la organización establece una distinción jerárquica entre los diferentes caracteres de los seres vivos. No basta con constatar la existencia o privación de un determinado elemento sino de valorar su relevancia vital. Esto dispone, en segundo lugar, una consideración decisiva a la funcionalidad que los caracteres prestan a los seres vivos, instancia que hace referencia, en último término, a una dinámica vital que busca la perpetuación y consolidación de una cierta estructura: el organismo. Por la misma razón, la biología moderna establece un contrato de sentido que vincula lo visible a lo invisible, lo expuesto a lo oculto, lo superficial a lo profundo. A la hora de establecer las relaciones entre los distintos seres vivos, este criterio romperá con toda la taxinomia de la historia natural. ${ }^{2}$ Se comienza a hablar entonces de procesos, facultades, sistemas, condiciones, cambios estructuras, vocablos todos que tienen lugar en un espacio distinto al de lo visible, desarticulando así la nomenclatura que anudaba con transparente comodidad la anatomía a lo observable. Todos estos factores concursan para que una cierta tonalidad vitalista finiquite las frías evidencias conquistadas por el mecanicismo.

Desde luego, esto traerá consecuencias que exceden el campo exclusivo de la biología. En efecto, la organización se transforma en la noción de referencia para y en consecuencia, el estudio de los seres se aborda a partir de la oposición entre viviente y no viviente, que coincide en buena parte con la de orgánico e inorgánico. Paulatinamente se hilvana una idea de vida que se opone y vincula a aquello que la amenaza: la vida aparece como una lucha obstinada en un medio al cual, sin embargo, se pertenece.

2 Sobre el tránsito desde la Historia Natural a la aparición de la biología y, el contexto discursivo que lo hace posible, véase sobre todo FOUCAULT, 2002, Capítulos V: Clasificar; y VIII: Los límites de la representación. 
Por cierto, esta consideración de lo viviente desde la oposición orgánico-inorgánico comunica una de las más intrincadas interrogantes acerca de la vida, de la cual, como ya hemos visto, Deleuze ha tomado noticia. Es en este punto cuando la figura del anatomista Xavier Bichat se transforma en un punto de inflexión.

Como ya anunciamos, en sus Recherches physiologiques sur la vie et la mort, Bichat (1852) comienza con una definición que va a influir severamente el debate filosófico: "La vida es el conjunto de funciones que resisten a la muerte" (p. 2). Bichat percibe que, con el dominio virgen de la anatomía y la fisiología modernas, se abre un campo de investigación que en nada se asemeja al de la materia inanimada. Si lo que interesa es el viviente, se debe renunciar por anticipado a un saber de carácter legislativo, de reglas inamovibles y aplicables de modo universal. La vida, en definitiva, es inaprensible en un sistema formal de cuantificaciones o esquematismos invariantes. Su nota esencial va a estar dada por esa capacidad de resistir que le permite ir compensando los procesos degenerativos naturales.

Por cierto, es Georges Canguilhem quien da un paso más en esta perspectiva. En Lo normal y lo patológico, el médico y filósofo establece una suerte de continuidad entre la vida y la muerte, toda vez que la primera gana en salud cuando es amenazada en su normatividad. La vida se muestra entonces como una polaridad dinámica: “[...] la enfermedad no es una variación en la dimensión de la salud; es una nueva dimensión de la vida." (CANGUILHEM, 1971, p. 141). De esta forma, el acento se pone en el impulso vital que trasgrede sus limitaciones de manera gradual pero imprevista.

Para Canguilhem el viviente está siempre enfrentándose con aquello que lo desafía. La vida consiste en un reto permanente a sus posibilidades de creación. De manera que la inestabilidad e irregularidad son fenómenos vitales constituyentes. La vida apunta más allá de la vida: es siempre un proyecto, una exploración que ella hace de sí misma y sus fronteras ${ }^{3}$.

3 Además, desde la posición de Canguilhem, en la medida que la vida consiste en la exploración de sus valores normativos, conlleva necesariamente la posibilidad del error. Este mismo estatuto dado al error implicará una resignificación de la noción 
De la mano de estos aportes, Foucault dedica un minucioso análisis en El nacimiento de la clínica a la anatomía patológica de Bichat. El capítulo "Abrid algunos cadáveres", permite el examen del momento en que la medicina se organiza en torno al trabajo con cadáveres inaugurando una mirada que integra la profundidad del cuerpo, es decir el volumen anatomo-clínico como punto de esclarecimiento.

La muerte se vuelve entonces iluminadora, pues adquiere un protagonismo epistemológico: ella es el bastión que permite dar razón de la salud y en última instancia, también de la vida. Así, la muerte se transforma en un observatorio privilegiado para comprender la vida, a la vez que la triada vida-enfermedad-muerte, forma un proceso indisociable y potente que fortalece los avances de la anatomía patológica. La frase de Foucault que encarna esta complicidad es: "La noche viva se disipa con la claridad de la muerte" (FOUCAULT, 2000, p. 209).

No obstante, la muerte es también una instancia vacía de significado para el médico, un instante oscuro que pone sobre la mesa la fragilidad del saber sobre la vida. La astucia de Bichat ha sido, según Foucault, la de volatilizar los aspectos fragmentarios de la muerte, diseminándola en una diversidad de espacios y momentos; se vuelve plural y corrosiva, se reparte en pequeños fallecimientos que el cuerpo padece silenciosa y alternadamente. El modo como Foucault explica este íntimo entramado da, según Deleuze, una nueva cara a la definición de Bichat de la vida como aquello que resiste.

Pero además en Foucault resalta su preferencia por aquel momento de singular imprevisibilidad en que la vida escapa de sí misma, en que rompe con su propia organización: “[...] la vida es aquello que es capaz de error, de allí su carácter radical. Y tal vez a causa de este dato, o de esta eventualidad fundamental, haya que dar una explicación sobre el hecho de que la anomalía atraviese la biología de punta a punta [...] (FOUCAULT, 2007, p. 56). Así vista, lejos del momento de la mera conservación del organismo, la vida lleva consigo la radicalidad

de monstruosidad que será entonces considerada como el depósito de desvíos y errancias de la misma vida en su continua apuesta por ampliar sus modos de existencia. La monstruosidad va plasmar los excesos de la vida cuya claridad se finiquita. Al respecto véase CANGUILHEM, 1976. También los comentarios de YUING, 2009, y MUHLE, 2010. 
del "error", del exceso que desafía todo orden y vuelve parcial toda organización.

Ahora bien, en el caso de Deleuze, esta consideración de la vida - diseminada y errante - está amarrada a una cierta visión del pensamiento que le otorga un estatuto diferente. En efecto, para Deleuze la vida siempre está ligada a una puesta en forma del pensamiento y a un estilo de vida. Dicho de otro modo, la vida nunca queda desarraigada de un cierto modo de vivirla que la pone en vínculo estrecho con la tarea de pensar, de escribir e incluso de hacer filosofía. Al mismo tiempo, las formas en que el pensamiento se implementa nunca están lejos de la vida que le soporta y que resiste a la base ${ }^{4}$. A este respecto, un asunto fundamental para Deleuze es el de advertir si el pensamiento es capaz de servir a la vida o si, al contrario, es aquello que la sujeta a un plano normativo. Así, a propósito de Nietzsche, Deleuze (2008) interroga el juego de relaciones que opone el conocimiento y la vida. Según ello, el conocimiento que limita y pone normas a la vida, aquel conocimiento que "ha acabado por erigirse en juez" (DELEUZE, 2008, p. 141) alude meramente a un momento reactivo, de repliegue de la vida. Llegado este punto, la distinción entre pensamiento y conocimiento se hace ineludible: el conocimiento es un pensamiento sometido a las leyes de la razón y que, en ese sentido, se ha postulado como instancia reguladora de la vida. Pero ello no es una constante. Para Deleuze la tarea consiste en buscar y fomentar un pensamiento que sea capaz de afirmar la vida y de establecer un contrato de sentido con su labor de resistencia. Deleuze señala su inclinación por:

Un pensamiento que fuese hasta el final de lo que puede la vida, un pensamiento que llevase a la vida hasta el final de lo que puede. [...] La vida sería la fuerza del pensamiento, pero el pensamiento el poder afirmativo de la vida. Ambos irían en el mismo sentido, arrastrándose

4 Para ser justos, es también Canguilhem quien ha elaborado un análisis en que la vida es cotejada junto al pensamiento. Para Canguilhem, vida, pensamiento y conocimiento se pertenecen íntimamente, razón por la cual, la conformación de conceptos como respuesta a problemas, constituyen modos de vida que, al igual que los seres vivos no humanos, nos ponen en condiciones específicas de existencia. Para un análisis sobre los eventuales aportes de Canguilhem a Deleuze en esta perspectiva, véase MARRATI (2008) y VERMEREN (2010). 
uno a otro y barriendo los límites, paso a paso, en el esfuerzo de una creación inaudita. Pensar significaría: descubrir, inventar nuevas posibilidades de vida (DELEUZE, 2008, p. 143).

De este modo, aquella dimensión de resistencia que, a partir de Bichat, se advertía como una mera función fisiológica, entra en continuidad estrecha con aquella resistencia que es capaz de enfrentarse al poder y evadirse de él. Es la misma vida la que, desde su inaprehensible fuerza, la que es capaz de sorprender y re-inventarse.

En cierta medida, esto da sentido a gran parte de la filosofía de Deleuze. Su proyecto puede ser entendido como una arremetida en favor de la vida, o si se prefiere, como el denuedo constante porque la vida se libere a sí misma. No debe entonces sorprender cuando Deleuze indique, a propósito del porvenir de los libros de filosofía: "Se escribe siempre para dar la vida, para liberar la vida allí donde está aprisionada, para trazar líneas de fuga." (DELEUZE, 1990, p.192). Para el filósofo, el estilo es aquello que marca su modo de ensamblar el pensamiento con su misma potencia, dando a luz algo que, de otro modo, estaría condenado a la existencia. Es por esta razón que a la hora de hacer filosofía, de crear algo nuevo con el pensamiento, el estilo es un modo de vida, y el punto de fuga, aquello que deja ilumina el espacio de ese lugar que el poder no puede anticipar, vale decir, el espacio de la creación y la resistencia. De esta manera, Deleuze termina reuniendo y conjugando en un mismo gesto la vida, la resistencia y el pensamiento:

En el acto de escribir, hay la tentativa de hacer de la vida algo que es más que personal, de liberar la vida de aquello que la aprisiona. [...] Se escribe en función de un pueblo porvenir que no tiene aún lenguaje. Crear no es comunicar sino resistir (DELEUZE, 1990, p. 196).

\section{Consideraciones finales}

¿Qué balance puede entonces establecerse? Volvamos al texto de 1995, "La inmanencia: una vida..." Como ha señalado oportunamente 
Agamben $^{5}$ (2007), el artículo indefinido - una - es indicativo de una condición relevante: el hecho de que Deleuze haga referencia a "una" vida señala su preferencia por un momento previo a cualquier identidad, arrancando todo coeficiente de personificación. La vida indica pura virtualidad y una potencia indeterminada. Ella es percibida como anterior a toda definición y por tanto escapa a la rigidez de un sistema de notas e incluso a un movimiento autopoiético ${ }^{6}$. Como es sabido, es Riderhood - el personaje de una novela de Dickens - el ejemplo elegido para mostrar como la vida contiene ese momento de impersonalidad. Quienes están salvando la vida de Riderhood no quieren en verdad salvar a Riderhood - ese canalla detestable - , están, por el contrario, salvando la posibilidad de que Riderhood no sea él mismo. De alguna manera están salvando aquello inactualizable que está integrado en la vida. Lo que parece guardar valor es aquello que no es un preciso modo de vida: "vida de pura inmanencia, neutra, más allá del bien y del mal, porque sólo el sujeto que la encarnaba en el medio de las cosas la volvía buena o mala." (DELEUZE, 2007, p. 38) Esto nos pone en camino de una síntesis.

Más que a una conformación delimitada - organismo, estructura, modelo - la vida dibuja una esfera siempre parcial no anticipada por ningún cierre. En 1966, a propósito de Bergson, Deleuze señalaba que

5 Es Agamben quien ha elaborado una interpretación de este problema al amparo de una "filosofía de la interpunción" que hace corresponder "dos puntos-inmanencia" y "puntos suspensivos-virtualidad". De este modo, La inmanencia: una vida... es una fórmula indivisible. Sin embargo, Agamben enfatiza el aspecto persistente y autorreferente de la vida, lo que a nuestro juicio, no es del todo oportuno. Para el italiano, la vida sería - ante todo -, esa fuerza que porfía y persevera en su mantenimiento. Por esta razón, la dimensión vegetativa, nutritiva y homeostática de la vida, es decir, la esfera de lo "meramente fisiológico", sería indicativa de lo más propio de su potencia: "El carácter más íntimo de la vida nutritiva no es, sencillamente el crecimiento, sino ante todo la autoconservación. Esto significa que, mientras la tradición médico-filosófica trata de distinguir cuidadosamente las potencias del alma [...] Deleuze retrotrae el paradigma sobre el esquema más inferior de la vida nutritiva" (AGAMBEN, 2007, p. 87). Pero es el momento de la imprevisibilidad el que se descuida en la lectura de Agamben. En efecto, pese a su persistencia, la vida en Deleuze no parece remitir por adelantado a ningún tipo de finalidad o conservación. También Espósito (2006) se ha detenido en el uso del artículo indeterminado en este texto de Deleuze. Espósito termina por identificar su sentido con el "motivo deleuziano de lo virtual" (ESPOSITO, 2006, p. 311), vale decir, aquella instancia pre y transindividual que permite la singularidad y que, en cuanto diferencia, es necesariamente impersonal.

6 Para una discusión acerca de las distancias del vitalismo respecto de la vida concebida como autopoiesis, véase KARMY, Rodrigo (2013). 
"la vida se determina esencialmente en el acto de superar unos obstáculos, de plantear y de resolver un problema." (DELEUZE, 1988, p. 13) La determinación de la vida responde a un desafío, a aquello que exige de ella su potencialidad. Pero al mismo tiempo ella "se compromete en un proceso de actualización", (DELEUZE, 2007, p. 40) de donde asoma el carácter siempre productivo de su multiplicidad y su irreductible fuerza de creación. Políticamente, es por ello es que, para Deleuze, el poder corre detrás de la vida, y ésta en su arremetida, se resiste bajo la forma de la innovación: "Es más, la última palabra del poder es que la resistencia es primera" (DELEUZE, 1987, p. 119). La resistencia no es otra cosa que el poder de la misma vida, poder vital que "no se deja detener en las especies, en los medios y en los caminos de tal y tal diagrama" (DELEUZE, 1987, p. 122).

¿Está resuelto entonces el estatuto que tiene la vida en cuanto coeficiente de resistencia? En absoluto. Sólo hemos podido profundizar las cuestiones e intentar mostrar los influjos, elementos y nudos teóricos que están comprometidos en este debate. En cierta medida, no es posible hablar de un "concepto" de vida en Deleuze. Su filosofía no establece lo que por ella debe entenderse, sino que se contenta con señalar aquellos puntos de fuga en los que el pensamiento se superpone a la vida para liberarla de aquello que la aprisiona. Es en ese sentido que la vida es resistencia: resistencia que se opone al poder tanto como a la muerte que ello significa. Esto no deja de plantear un desafío para toda filosofía que coloque a la vida en el centro de su preocupación. Siguiendo a Deleuze, Isabelle Stengers (2000) indica que si la resistencia se constituye como poder de la vida, no puede definirse por un objeto. Ello sería una trampa del poder. Pero inversamente, si la vida deviene resistencia, ello exige al pensamiento ser capaz de mutar y abandonar las alternativas excluyentes por la agregación de posibilidades ${ }^{7}$.

7 "Si la vida deviene resistencia, es el pensamiento de la resistencia el que debe mutar, abandonar los «0 ...0 . ..» por el «y ... y...». (STENGERS, 2000, p. 100). 


\section{Referencias}

AGAMBEN, G. La inmanencia absoluta. In: GIORGI, G.; RODRIGUEZ, F. Ensayos sobre biopolítica. Excesos de vida. Buenos Aires: Paidos, 2007.

BICHAT, X. Recherches physiologiques sur la vie et la mort. Paris: Victor Masson, 1852. Acceso en: 20 de mayo de 2015 del archivo digital de la Biblioteca Nacional de Francia. Disponible en: <http://gallica.bnf.fr/ark:/12148/bpt6k6275881c>.

BROSSAT, A. Droit à la vie? París: Seuil, 2010.

CANGUILHEM, G. Lo normal y lo patológico. Buenos Aires: SXXI editores, 1971.

CANGUILHEM, G. El conocimiento de la vida. Barcelona: Anagrama, 1976.

DELEUZE, G. Foucault. Barcelona: Paidós, 1987.

DELEUZE, G. Pourparlers. París: Les Éditions de Minuit, 1990.

DELEUZE, G. El bergsonismo. Madrid: Cátedra, 1988.

DELEUZE, G. El hombre: una existencia dudosa. In: La isla desierta y otros textos. Valencia: Pre-textos, 2005.

DELEUZE, G. Nietzsche y la filosofía. Barcelona: Anagrama, 2008.

DELEUZE, G. La inmanencia: una vida..., In: GIORGI, G.; RODRIGUEZ, F. (comps). Ensayos sobre biopolítica. Excesos de vida. Buenos Aires: Paidos, 2007.

ESPOSITO, R. Bios. Biopolitica y Filosofía. Buenos Aires: Amorrortu, 2006.

FOUCAULT, M. Historia de la sexualidad I. La voluntad de saber. Buenos Aires: Siglo XXI editores, 1998.

FOUCAULT, M. El nacimiento de la clínica. Una arqueología de la mirada médica. Buenos Aires: Siglo XXI, 2000.

FOUCAULT, M. Defender la sociedad. Curso en el Collège de France 1975-1976. BuenosAires: Fondo de Cultura Económica, 2001.

FOUCAULT, M. Las palabras y las cosas. Una arqueología de las ciencias humanas. Buenos Aires: Siglo XXI, 2002. 
KARMY, R. ¿Es la vida un "sistema”? Para una crítica de la "biología del conocer". Paralaje. Revista de Filosofía, pp. 181-192. Año 6, n 9, 2013.

MARRATI, P. La nouveauté de la vie. In : Rue Descartes. Collège international de Philosophie, n. 59, p. 32-41, 2008.

MISHIMA, Y. El marino que perdió la gracia del mar. Madrid: Alianza, 2003.

MOREY, M. Prólogo a FOUCAULT, M. Diálogos sobre el poder y otras conversaciones. Madrid: Alianza, 1981.

MUHLE, M. Sobre la vitalidad del poder: una genealogía de la biopolítica a partir de Foucault y Canguilhem. In: LEMM, V. (editora). Michel Foucault: neoliberalismo y biopolítica. Santiago: Ediciones Universidad Diego Portales, 2010.

NAPOLI, P. Sur le droit et la vie. Revista Multitudes, n 1, p. 58 - 63. Mars 2000.

STENGERS, I. Si la vie devient résistance... Revista Multitudes, n. 1, p. 99 -101. Mars 2000.

VERMEREN, P. El error, el concepto, lo viviente. Georges Canguilhem en el momento filosófico francés de la segunda mitad del siglo veinte. Revista Pensamiento de los Confines, Buenos Aires: Guadalquivir, n 26, p. 75-86, 2010.

YUING, T. La vida y sus resistencias: retrospectivas, pesquisas y derivas para una noción. Revista Paralaje, n. 3, v. 11 p. 113-123, 2009.

YUING, Tuillang. Biopolítica y clínica: notas para una pregunta por el individuo. In: YUING, T. y KARMY, R. (editores), Biopolítica, gobierno y salud pública. Miradas para un diagnóstico diferencial. Santiago: Ocho Libros y Escuela de Salud Pública de la Universidad de Chile. p. 89-109, 2014.

Recibido: $12 / 12 / 2016$

Recebido 12/12/2016

Aprobado: 16/02/2017

Aprovado: 16/02/2017 